\title{
ELABORAÇÃO DE UMA CERVEJA TIPO ALE UTILIZANDO MELÃO COROÁ (SICANA ODORÍFERA (VELL.). NAUDIN) COMO ADJUNTO DO MALTE.
}

\author{
Flávia Santana Santos ${ }^{\mathbf{1}}$; Giovani Brandão Mafra de Carvalho ${ }^{2}$. \\ 1. Bolsista PIBITI/CNPq, Graduando em Engenharia de Alimentos, Universidade Estadual de Feira de Santana, e- \\ mail: santos_flavinha1996@hotmail.com \\ 2. Orientador, Departamento de Tecnologia, Universidade Estadual de Feira de Santana, e-mail: \\ gbmafra@yahoo.com.br
}

PALAVRAS-CHAVE: Fermentação; cervejas não-convencionais; adjuntos de malte.

\section{INTRODUÇÃO}

A elaboração de cervejas utilizando adjuntos especiais tem sido uma nova tendência para suprir às exigências do mercado, e um dos novos adjuntos que pode ser utilizado é o melão coroá (Sicana odorífera (Vell.). Naudin).

Esse trabalho busca elaborar uma cerveja Ale utilizando como adjunto o melão coroá a fim de desenvolver um processo cervejeiro economicamente viável, contribuir na diversificação da linha de produtos, assim como valorizar a matéria-prima, que atualmente não tem tido um aproveitamento notável.

\section{METODOLOGIA}

Extração e condicionamento da polpa de Melão Coroá Coroá (Sicana odorífera (Vell.). Naudin).

Selecionar em laboratório os frutos, lavar em água corrente, sanitizar em solução de hipoclorito de sódio a 50 ppm e fragmentar os mesmos manualmente. Em seguida, inserir na despolpadeira para realização da homogeneização e trituração e, logo após, as polpas acondicionar em embalagens flexíveis de polietileno de baixa densidade e armazenar em freezer a $-18^{\circ} \mathrm{C}$.

Caracterização da polpa do Melão Coroá (Sicana odorífera (Vell.). Naudin) e dos Mostos

O mosto foi preparado conforme metodologia desenvolvida por CARVALHO, 2009.

Condições de fermentação

A fermentação para cada ensaio foi conduzida em fracos Erlenmeyer, contendo $250 \mathrm{~mL}$ de mosto, adaptados com válvulas airlock com volume útil de $500 \mathrm{~mL}$, inoculados com levedura comercial e incubados a $15^{\circ} \mathrm{C}$ e $22^{\circ} \mathrm{C}$.

Concentração celular

A concentração de células em suspensão foi determinada com base na metodologia de contagem em câmara de Neubauer.

Concentração de etanol e consumo de extrato Aparente

A concentração de etanol e consumo de extrato aparente na amostra foi determinada em equipamento analisador de cerveja.

Caracterização do mosto 
Metodologia dessas análises foi segundo instituto Adolfo Lutz, 2008.

Produção da cerveja em escala piloto

Foi preparada conforme metodologia desenvolvida por CARVALHO, 2009.

Análise sensorial

Foi desenvolvida segundo Stone e Sidel (1985).

\section{RESULTADOS E/OU DISCUSSÃO}

\section{Caracterização da polpa de melão caroá}

Os resultados encontrados para as características físico-químicas da polpa de melão caroá estão apresentadas na tabela abaixo.

Tabela 1. Características físico-químicas da polpa de melão de caroá (Sicana odorífera) e dados da literatura.

\begin{tabular}{|c|c|}
\hline Teor de sólidos solúveis $\left({ }^{\circ}\right.$ Brix $)$ & $12,10 \pm 0,06$ \\
\hline Açúcares redutores $(\%)$ & $9,04 \pm 0,07$ \\
\hline Carboidratos totais (\%) & $10,54 \pm 0,03$ \\
\hline $\mathrm{pH}$ & $6,20 \pm 0,02$ \\
\hline $\begin{array}{c}\text { Acidez total titulável (\% em ácido } \\
\text { cítrico) }\end{array}$ & $0,20 \pm 0,07$ \\
\hline Proteína (\%) & $1,09 \pm 0,13$ \\
\hline Lipídeos $(\%)$ & $0,35 \pm 0,05$ \\
\hline
\end{tabular}

A polpa do melão de caroá teve teor de sólidos solúveis igual a $12,1^{\circ} \mathrm{Brix}$ (Tabela 1), apresentando-se adequado para o processo fermentativo da cerveja. Então, não se fez necessário executar o processo de chaptalização da polpa, que segundo Dias, Schwan e Lima (2003), consiste em corrigir o teor de sólidos solúveis a partir do uso de uma solução de sacarose. Jaramillo et al. (2011) encontraram um valor de $13^{\circ}$ Brix, próximo ao encontrado neste trabalho.

\section{Concentração celular e densidade do mosto}

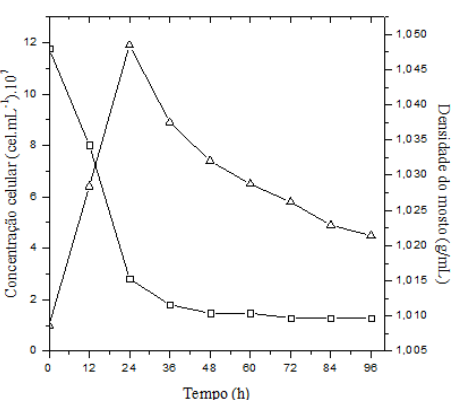

(A)

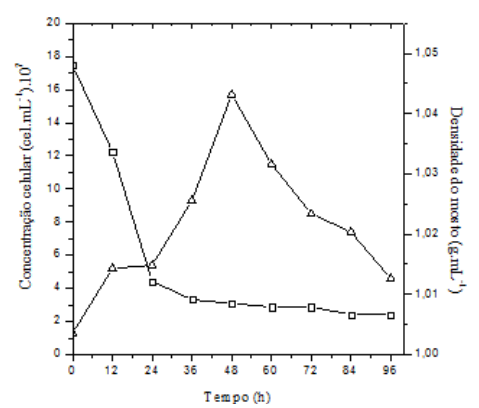

(B)

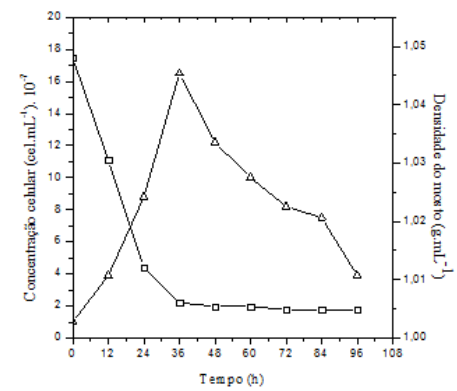

(C)

Figura 1- Comparação entre a concentração de células em suspensão $(\mathrm{cel} / \mathrm{mL})(\Delta)$ e a redução da densidade do mosto $(\mathrm{g} / \mathrm{mL}$ ) (口) em quatro experimentos: (A) com 10\% de adjunto; (B) com 30\% de adjunto; (C) com $49 \%$ de adjunto. 
O mosto com maior concentração de adjunto (49\%), a concentração celular correspondeu a $1,65 \times 10^{8} \mathrm{cel} / \mathrm{mL}$ após $36 \mathrm{~h}$, seguido por $1,57 \times 10^{8} \mathrm{cel} / \mathrm{mL}$ após $48 \mathrm{~h}$ no mosto com $30 \%$ de adjunto; $1,19 \times 10^{8}$ cel/mL após 24 h no mosto com $10 \%$ de adjunto.

\section{Concentração de etanol e densidade do mosto}

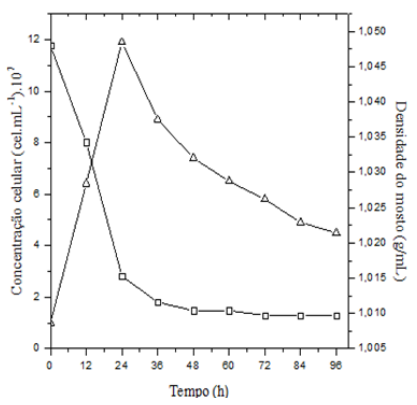

(A)

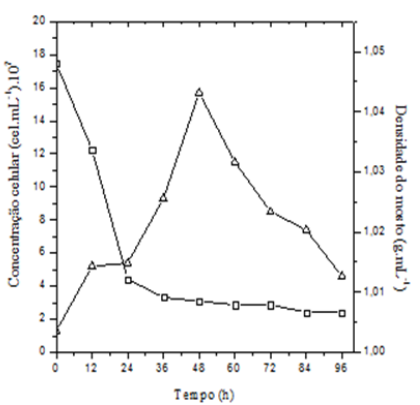

(B)

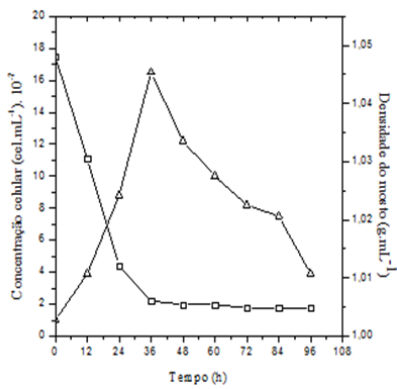

(C)

Figura 2 - Perfis de concentração de etanol $(\mathrm{g} / \mathrm{L})(\circ)$ e de densidade do mosto $\left(\mathrm{g} / \mathrm{cm}^{3}\right)(\square)$ nos seguintes mostos: (A) com $10 \%$ de adjunto; (B) com 30\% de adjunto; (C) com $49 \%$ de adjunto e desconsiderar este.

A partir da Figura 2, pode-se notar que durante o processo fermentativo, à medida que ocorre a produção de etanol, há uma redução da densidade do mosto. Conforme Carvalho (2009), a redução da densidade está associada tanto ao consumo do substrato para manutenção e construção celular quanto à formação de produtos menos densos e/ou voláteis. Logo, a densidade do mosto tende a diminuir com a produção de etanol, resultante do consumo dos açúcares.

\section{Caracterização físico-química da cerveja com $49 \%$ de adjunto}

A cerveja elaborada com $49 \%$ de adjunto foi caracterizada físico-quimicamente de acordo com os dados apresentados na Tabela 2.

Tabela 2 - Análise físico-química da cerveja com $49 \%$ de adjunto.

\begin{tabular}{|c|c|}
\hline Parâmetro & Média \pm DP* \\
\hline Ph & $4,3 \pm 0,11$ \\
\hline Proteína bruta (\%) & $0,21 \pm 0,08$ \\
\hline Cor (EBC) & $14,00 \pm 0,15$ \\
\hline Amargor (BU) & $10,2 \pm 0,11$ \\
\hline
\end{tabular}

\section{Análise Sensorial}

A cerveja produzida com $49 \%$ de adjunto (melão de caroá) teve uma aceitação positiva, a partir da Figura 3, pode-se observar que dos 70 provadores que participaram da análise sensorial, 77,14 \% gostaram do produto, porém em relação à intensidade, destacou-se o grupo que afirmou ter gostado moderadamente, representando 57,14\%. Os provadores que demonstraram ter desgostado do produto, são representados por $18,57 \%$ dos participantes, sendo que destes, a maioria (10\%) desgostou moderadamente. E os outros 4,29\% posicionaram-se de forma indiferente.

Em relação à intenção de compra (Figura 4), obteve-se consequentemente um resultado positivo, uma vez que $72,86 \%$ dos provadores comprariam o produto, 
destacando se deste grupo 61,43\% que afirmaram que provavelmente comprariam. Os provadores que não comprariam o produto representaram $10 \%$ dos provadores, sendo que a maior parte deste provavelmente não comprariam. Um grupo de 17,14\% mostrouse em dúvida.

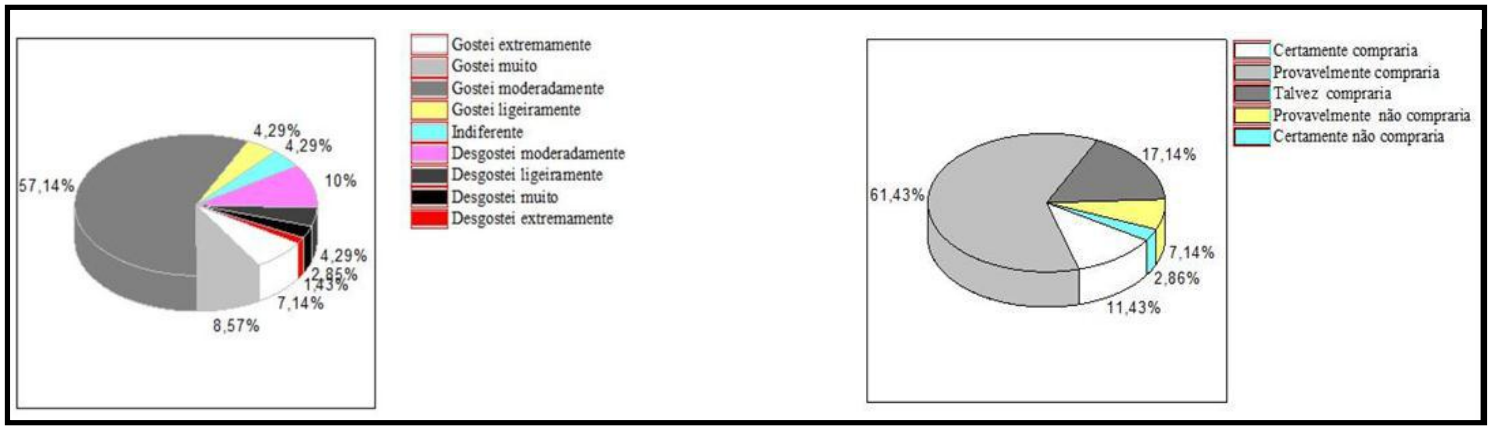

Figura 3- Resultado do teste de aceitação da

Figura 4- Resultado da intenção de compra dos cerveja com melão de caroá. provadores em relação à cerveja.

\section{CONCLUSÃO}

Com o presente projeto de iniciação cientifica, foi possível notar que a utilização da polpa de melão caroá como adjunto na produção de cerveja tipo "Ale”, obteve resultados positivos quanto ao processo fermentativo, onde a mesma favoreceu uma quantidade ideal de açúcares fermentativos, uma vez que estes são substratos para as leveduras durante a fermentação, possibilitando, principalmente, a formação do etanol. A produção da cerveja utilizando $49 \%$ de adjunto (melão de caroá), apresentou melhores resultados quanto a produção de etanol, visto que nesta concentração de adjunto, notou-se uma maior redução da densidade, o que proporcionava uma maior produção de etanol quando comparado a adição de concentrações menores de adjunto (10\% e 30\%). A cerveja produzida com $49 \%$ de adjunto de melão de caroá, apresentou um nível de aceitação também positiva, como foi possível comprovar com os resultados da análise sensorial do produto pelos provadores.

\section{REFERÊNCIAS}

ARAÚJO, F. B.; SILVA, P. H. A.; MINIM, V. P. R. Perfil sensorial e composição físico-química de cervejas provenientes de dois segmentos do mercado brasileiro. Ciência e Tecnologia de Alimentos, v. 23, n. 2, p. 121-128, 2003.

CARVAlHO, G. B. M. Obtenção de Cerveja Usando Banana como Adjunto e Aromatizante. 2009. Tese (Doutorado em Biotecnologia Industrial), Universidade de São Paulo, Lorena, 2009. 163f.

DIAS, D.R; Schwan, R. F; LIMA, L.C.O. (2003). Metodologia para elaboração de fermentado de cajá (Spondias mombin L). Ciência e tecnología de Alimentos.

JARAMILLO, J., et al. Some like it hot: the influence and implications of climate change on coffee berry borer (Hypothenemus hampei) and coffee production in East Africa. Plos One, v.6, p. e24528, 2011.

INSTITUTO ADOLFO LUTZ - IAL. Normas analíticas do Instituto Adolfo Lutz: métodos químicos e físicos para análise de alimentos. 3. ed. São Paulo: O Instituto, 1985. 